\title{
Short-term memory in children as a function of display size'
}

R. C. CALFEE, E. MAVIS HETHERINGTON AND PHYLLIS WALTZER

UNIVERSITY OF WISCONSIN

Display size was varied in a card-guessing game with young children by presenting either 3,4 or 5 animal cards in serial order, and testing for recall on one of the cards. Marked recency effects were observed at all stages of training, and during the early trials, some primacy was noted. Retrieval appeared to be an all-or-none phenomenon, in contrast to previous studies with 8-item displays, which found generalization and above-chance guessing on the second choice.

Recent studies by Atkinson et al (1964) and Hansen (1965) have used a card-guessing game to investigate short-term memory (STM) processes in young children. In this technique, a series of cards with colored drawings of animals are presented one at a time in serial order. Each card, after being presented to the child, is turned face down so that a horizontal array is formed. The child is then shown a separate cue card, and is asked to turn over the matching card in the face-down array. In both of the studies referred to above, an 8-card list was used.

A pronounced recency effect was evident in the Atkinson et al study (the last card laid down had the highest probability of being chosen correctly as a match), but no primacy was observed. Generalization effects were also found; when an error was made, the incorrect choice tended to be close to the correct position. In the Hansen study, presentation rate was varied ( 1 sec. and 3 sec.) with the result that the slower rate improved recall of the last cards presented, and the faster rate improved recall of the first cards. Marked recency effects were observed with both rates. There was also a slight primacy effect, especially at the slower rate.

The present study was designed to investigate the effects of within-subject variation in list length on STM of preschool children using a similar experimental task. Also of interest was the question of whether primacy and recency effects varied over trials. Murdock (1964) has shown that significant changes in the shape of the serial position curve over trials may occur when repeated measures are used in STM studies. He found primacy as we ${ }^{11} i$ as recency during early trials, but the primacy disappeared in the later stages of training.

Method

The $\mathrm{S} s$ were 38 preschool children between 3.5 and 5 years of age $(\bar{X}=4.1, S D=.51)$ from the Unitarian Society Nursery School, Madison, Wisconsin. Each child was asked if he would like to play a game; if the child was willing, he was brought to the experimental room. There he was shown a collection of small toys, and told that he might choose one toy as a prize for playing the game well. All Ss received the toy of their choice at the end of the session.

The stimulus materials consisted of a set of 11 brightly colored animal cards. Each card was shown to $S$, who was asked to name the animal until $\mathrm{S}$ was familiar with each card in the deck. The experiment consisted of 24 trials, each trial requiring about $1 \mathrm{~min}$, for a total session time of about $1 / 2 \mathrm{hr}$.

On each trial a subset of 3,4 or 5 cards was randomly seie $\cdots$ for presentation. The randomization for a child was arranged so that each display size was used for 8 trials, and each serial position was tested at least once for every display size. The selected cards were shown one at a time to $\mathrm{S}$ for a $1-\mathrm{sec}$. interval, $\mathrm{S}$ called out the name of the animal, and then the card was placed face-down in a horizontal array in front of $\mathrm{S}$. After the last card was presented, a cue card which was identical to one member of the presentation set was held up, and $\mathrm{S}$ was asked to turn up the matching card in the array. If the response was incorrect, $S$ continued to turn up additional cards until a match was obtained. The intertrial interval was about $40 \mathrm{sec}$., during which time $E$ arranged cards for the rext trial and chatted with $\mathrm{S}$.

\section{Results and Discussion}

Figure 1 presents the mean proportion of correct responses at each position for the three display sizes. Position 1 corresponds to the last card displayed prior to the retention test. The proportion of correct responses is a decreasing function of the number of cards intervening between the test position and recall. The probability that the last card in the display is correctly identified when it is the test position varies between .85 and .90 , and appears to be unrelated to display size. It may be that this performance represents the best obtainable with preschool children in this task. Hansen's 5 yr. olds gave about .65 correct responses at Position 1 with an 8-item list, and the corresponding value in the Atkinson et al study was about .90 . The proportion of correct responses in Position 2, the

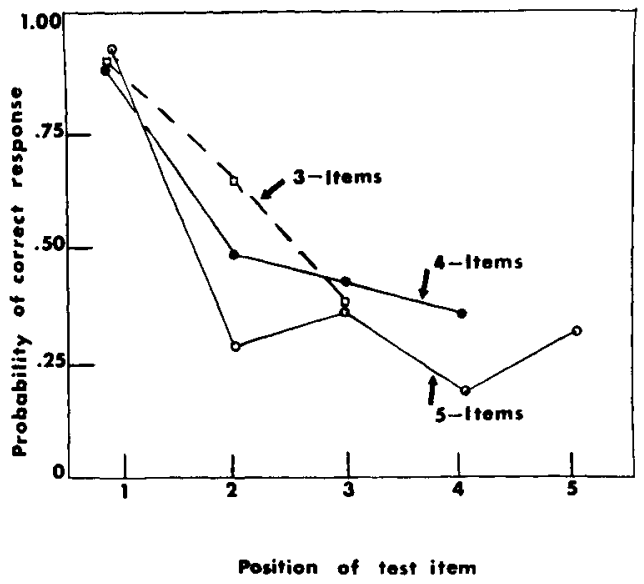

Fig. 1. P'roportion of items correctly recalled on first attempt at each serial position for three display sizes. 
Table 1. Frequency of first response in each position for each test position and error frequency distributions for three display sizes.

\begin{tabular}{|c|c|c|c|c|c|c|}
\hline \multirow{2}{*}{$\begin{array}{l}\text { First } \\
\text { Response }\end{array}$} & \multirow{2}{*}{1} & \multicolumn{3}{|c|}{ Test Position } & \multirow{2}{*}{5} & \multirow{2}{*}{$\begin{array}{l}\text { Total } \\
\text { Errors }\end{array}$} \\
\hline & & 2 & 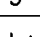 & 4 & & \\
\hline \multicolumn{7}{|c|}{ 3- Item List } \\
\hline 1 & 93 & 12 & 10 & - & - & 22 \\
\hline 2 & 12 & 72 & 61 & - & - & 73 \\
\hline 3 & 4 & 22 & 42 & - & - & 26 \\
\hline \multicolumn{7}{|c|}{ 4- Item List } \\
\hline 1 & 71 & 14 & 4 & 4 & - & 22 \\
\hline 2 & 7 & 40 & 32 & 16 & - & 45 \\
\hline 3 & 2 & 16 & 35 & 33 & - & 51 \\
\hline 4 & 3 & 11 & 11 & 29 & - & 25 \\
\hline \multicolumn{7}{|c|}{ 5- Item List } \\
\hline 1 & 62 & 9 & 8 & 5 & 1 & 23 \\
\hline 2 & 3 & 23 & 15 & 14 & 6 & 38 \\
\hline 3 & 1 & 25 & 25 & 23 & 26 & 101 \\
\hline 4 & 1 & 8 & 12 & 13 & 8 & 42 \\
\hline 5 & 0 & 2 & 6 & 10 & 22 & 18 \\
\hline
\end{tabular}

next-to-last card presented, varies from .34 to .67 , and is monotonically related to display size. As the display size is decreased (i.e., as fewer cards are presented), $S$ is more likely to recall the card presented in Position 2, and the amount of this improvement is greater than can be accounted for by changes in the guessing rate.

The number of times each position was the first choice at each test position is presented in Table 1 for the three display sizes. Investigation of these data indicates that, unlike Atkinson's study, no generalization around the correct position was observed. Rather, there was a tendency at all display sizes to choose one of the middle cards in the array when an error occurred.

Since there appeared to be no generalization with the relatively small display sizes used in this study, the hypothesis was entertained that, when the cue card was presented, either the child was able to retrieve the position of the matching card from a short-term store, or else the child simply guessed at random according to the non-uniform marginal distribution in Table 1. The following analysis was carried out with this hypothesis in mind. In Table 2 is presented the mean number of cards turned up before a correct match was obtained at each test position, based on those

Table 2. Mean number of cards turned up before a correct match. given that the first response was an error, observed and predicted (in parentheses).

\begin{tabular}{lccccc} 
List & \multicolumn{5}{c}{ Test Position } \\
Length & 1 & 2 & 3 & 4 & 5 \\
\hline 3 & 2.69 & 2.12 & 2.30 & - & - \\
& $(2.65)$ & $(2.25)$ & $(2.53)$ & & \\
4 & 3.00 & 2.56 & 2.45 & 3.12 & - \\
& $(3.14)$ & $(2.58)$ & $(2.70)$ & $(3.18)$ & \\
5 & 3.60 & 3.07 & 2.71 & 2.81 & 3.68 \\
& $(3.62)$ & $(3.31)$ & $(2.80)$ & $(3.55)$ & $(3.98)$ \\
\hline
\end{tabular}

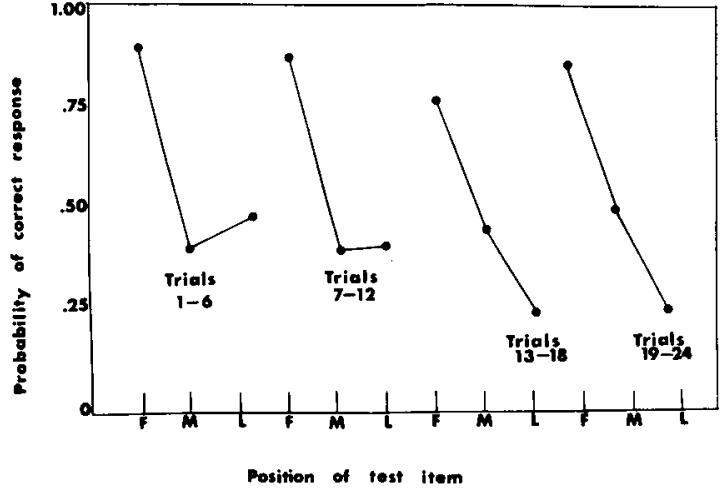

Fig. 2. Serial position curves in 6-trial blocks over display sizes for first (F), last (L), and all middle (M) test positions.

trials when the first response was incorrect. The predicted values are obtained from the all-or-none retrieval hypothesis mentioned above, and the empirical error distributions in Table 1. (The probabilities were renormalized as cards were drawn successively.) The predicted values in Table 2 give a reasonably good account of the observed data. If there is any noticeable trend to the discrepancies, the predicted values tend to be slightly higher than the observed, which might indicate that the subject may occasionally have some idea about the correct position, even though the first response is wrong. This interpretation would accord with the finding of both Atkinson et al and Hansen that the second choice, following an initial error, tends to be correct more frequently than chance would predict.

In order to evaluate changes in the serial position curve over trials, the probability of an initial correct choice was found for the first (F) and last (L) positions, and for all middle (M) positions taken together, averaged over display sizes in 6-trial blocks. The results of this analysis, presented in Fig. 2, are in agreement with Murdock's (1964) results; primacy as well as recency is observed during the first two blocks, following which there is only recency.

Comparison of the present study with the results of Atkinson et al and Hansen indicates that children may process long and short lists in somewhat different ways; additional information will have to be obtained by within-subject variation of list length over a wider range in order to specify these differences.

\section{References}

Atkinson, R. C., Hansen, D. N., \& Bembach, H. A. Short-term memory with young children. Psychon. Sci., 1964, 2, 255-256.

Hansen, D. N. Short-term memory and presentation rates with young children. Psychon. Sci., 1965, 3, 253-254.

Murdock, B. B., Jr. Proactive inhibition in short-term memory. $J$. exp. Psychol., 1964, 68, 184-189.

\section{Note}

1. This research was supported in part by the Research Committee of the Graduate School of the University of Wisconsin with funds provided by Wisconsin Alumni Research Foundation, and in part by Grant S-321 from the Office of Education. 